\title{
Comparison of Blood Lipids, Lipoproteins, Anthropometric Measures, and Resting and Exercise Cardiovascular Responses in Children, 6-7 Years Old ${ }^{1}$
}

\author{
Thomas B. Gilliam, Patty S. Freedson, Susan E. MacConnie, \\ David L. Geenen, and Albert E. Pels III \\ 3040 Central Campus Recreation Building, Department of Physical Education, \\ The University of Michigan, Ann Arbor, Michigan 48109
}

\begin{abstract}
The purpose of this investigation was to determine sex differences and interrelationships in anthropometric, blood lipids and lipoproteins, steady rate and maximal bicycle ergometric measures in boys $(N=38)$ and girls $(N=28)$ ages 6 to 7 years. After adjusting for a significantly $(P<0.05)$ higher sum of skinfold measure for the girls, significant $(P<0.05)$ sex differences were obtained for high-density lipoprotein cholesterol (HDL-C), resting heart rate, and steady-rate heart rate. Lower HDL-C values (43.3 vs $49.6 \mathrm{mg} / \mathrm{dl}$ ) for the girls accounted for their lower cholesterol since no sex differences were found for low-density lipoprotein cholesterol (LDL-C). Following $4 \mathrm{~min}$ of steady-rate bicycling at $90 \mathrm{kgm}$, girls had higher heart rates (131 vs 119 beats $\left.\cdot \mathrm{min}^{-1}\right)$ whereas no differences $(P>0.05)$ existed in preexercise and maximal heart rates. Multiple regression analyses resulted in weak but significant $(P<0.05)$ prediction equations for cholesterol and cumulative work performed on the bicycle. A significant $(P<0.05)$ negative correlation between HDL-C vs triglycerides $(r=0.46)$ was obtained for the girls. These data indicate that sex differences exist for selected ergometric, anthropometric, and blood lipid and lipoprotein measures as early as 6 years. Also, the association among blood lipid and lipoprotein measures may differ between boys and girls.
\end{abstract}

Coronary heart disease (CHD) risk factors such as hypertension, obesity, elevated blood lipids, and inadequate physical activity have been reported to be prevalent in children $(9,10,14,15,25,29,36,37)$. Descriptive studies concerning blood lipid levels have received the most attention in the literature. These investigations have established normative data for several blood lipid parameters to classify individuals into categories which can be used to predict one's propensity toward the pathogenesis of atherosclerosis. At present, extensive normative data are available for adult (22) and child $(8,12,13,24,25,29)$ populations.

The association between the blood lipids and other risk factors has not been thoroughly studied. In an earlier investigation from our laboratory, we reported the interrelationships between some CHD risk factors in a relatively small sample of 7 to 12 year-old boys and girls (14). It was shown that the risk factors are apparently independent from each other as indicated by the low correlation coefficients $(r=0.30)$. However, it has been suggested that the true associations among the risk factors can be masked by the onset of puberty consequent to growth (24,

${ }^{1}$ This study was supported in part by NHLBI Grant RO1-HL22886-01. 
31, 33). Thus, correlations reported in cross-sectional studies involving different stages of growth and development might not reflect the true relationships.

In the present study, we have attempted to eliminate the dependent effect of pubescence on CHD risk factors by examining the differences between sex for certain CHD risk factors in prepubescent 6- and 7-year-old children.

\section{METHODOLOGY}

\section{Subjects}

Parental consent was obtained for 66 white volunteers ( 38 boys, 28 girls) ages 6 to 7 years. The children live in a community that is predominantly white $(99 \%)$ with $71 \%$ of the people identified as blue-collar workers and the remainder as white-collar workers. When the parents were asked why they enrolled their child in the program, one of three reasons were given: (a) family history of CHD, (b) family obesity problem, and (c) interest in CHD prevention. All rights and privileges of each child according to the University of Michigan Human Subject Approval Committee were maintained.

\section{Testing}

All testing took place in the fall of 1979. Except for the drawing of the blood, the tests were completed on each child during two 1-hr sessions over a 2-day period. Resting blood pressure, ECG, and anthropometric measures were obtained the first day, and the performance test was administered the second day. Blood drawing occurred 1 week later between 7:30 and 8:30 AM, after a 12-hr fasting period. Parameters measured for each subject included:

I. Anthropometry. Height, weight, and skinfold (scapula, abdomen, iliac, and triceps) measurements were obtained on all children. The skinfold measurements were taken in duplicate with a Lange skinfold caliper according to the landmarks described by Behnke and Wilmore (5). If the paired measurements were not within $5 \%$ of each other, they were repeated. The average of the four measurements was then summed for data analysis (sum of skinfold). Body surface area (BSA) was calculated from a formula derived by DuBois (11).

II. Blood chemistry. With the child in the supine position, a 20-cc venous, $12-\mathrm{hr}$ fasting blood sample was drawn by a pediatrician from the medial cubital vein into a vacutainer containing $1.5 \mathrm{mg} / \mathrm{ml}$ disodium EDTA. The plasma was separated by centrifugation and stored at $4^{\circ} \mathrm{C}$ until processed within $2 \mathrm{hr}$. After withdrawal, the chylomicrons were removed (20) and the VLDL lipoproteins separated at $d=1.006 \mathrm{~g} / \mathrm{ml}(\mathrm{NaCl})$ in a Beckman ultracentrifuge Model L2 with a 50T rotor at $40,000 \mathrm{rpm}$ for $18 \mathrm{hr}$ at $15^{\circ} \mathrm{C}$. From the infranate, the HDL and LDL fractions were separated by the precipitation of the LDL fraction with heparin-manganese chloride (26). The plasma chylomicrons, VLDL, total HDL and LDL, and HDL fractions were analyzed for total cholesterol and triglycerides $(6,7)$. Both internal and external standards were run in parallel with the analyses. The cholesterol and triglyceride laboratory techniques have the approval of the Lipid Research Clinic Program (26). All analyses were performed at the Lipid Metabolism Laboratory, the University of Michigan.

III. Resting blood pressure. Resting blood pressure was determined by one of 
three pediatricians using a mercury manometer with a child's cuff. Systolic and diastolic readings were recorded as Phase I and Phase IV Korotkoff sounds, respectively. Following $5 \mathrm{~min}$ of rest in the seated position, three readings were taken with 1 to 2 min between readings in a quiet, comfortable room. The average of the three readings was used in the data analyses. The recordings were made with the child in the seated position using the right upper arm.

$I V$. Exercise performance. Each subject performed a continuous submaximal and maximal exercise test on a child's Monark bicycle ergometer. Subjects pedalled at a constant rate of 60 revolutions per minute $(60 \mathrm{rpm})$ paced by a visual/auditory metronome. To obtain an accurate count of pedal revolutions, a microswitch counter assembly mounted on the frame of the bicycle was activated by each pedal revolution. The initial frictional resistance (first minute) was $0.0 \mathrm{~kg}$ with the resistance set at $0.25 \mathrm{~kg}(90 \mathrm{kgm})$ for the following $4 \mathrm{~min}$ (steady rate, minutes 2 through 5). The resistance was then increased $0.25 \mathrm{~kg}$ for each subsequent minute until volitional exhaustion. Recovery lasted $5 \mathrm{~min}$ postexercise with an active recovery the first minute $(45 \mathrm{kgm})$. Heart rate was continuously monitored using a bipolar $\left(\mathrm{V}_{5}\right)$ EKG.

$V$. Twelve-hour heart rate. Each subject wore a holter device (Ambulatory Monitoring Inc.) during a weekday to record continuous heart rates on a cassette tape for $12 \mathrm{hr}$ from 8:00 AM to 8:00 $\mathrm{PM}$. The parents were instructed to periodically (every 1-2 hr) ask their child the types of activities participated in (i.e., sitting, running, outside playing, eating) and to record this information on an activity log. The cassette tape was replayed via an Oxford PB-2 replay device. The analog signal was interpreted using a Cromemco computer programmed to read the $\mathbf{R}-\mathbf{R}$ interval at 1-min increments. The minute-by-minute heart rates were then transmitted from the Cromemco computer to the Michigan Terminal System (MTS) for data processing and analysis. Six tapes were randomly selected and read on an independent replay unit to determine validity of the Cromemco program. The two independent readings of the minute-by-minute heart rates yielded results within \pm 3 beats $\cdot \min ^{-1}$.

\section{Statistics}

Statistical analyses included descriptive analyses on all variables and Student $t$ tests (two-tailed) to compare sexes. Multiple regression analyses and single-order correlations were also performed on selected variables. A probability level of 0.05 was used for significance.

\section{RESULTS}

Table 1 presents the physical characteristics for the boys and girls. As can be observed, height and weight were not different $(P>0.05)$ between the sexes; however, the girls had a significantly $(P<0.05)$ greater sum of skinfold measure (SSF), i.e., 43.3 vs $30.5 \mathrm{~mm}$. When expressing the mean height and weight measures by sex as percentile scores according to the National Center on Health Statistics, both sexes were slightly larger than the national sample (mean height percentile: $52.9 \%(\mathrm{~B}), 50.2 \%(\mathrm{G})$; mean weight percentile: $51.6 \%(\mathrm{~B}), 60.2 \%(\mathrm{G})$ ) 
TABLE 1

Physical Characteristics for the Boys $(N=38)$ and Girls $(N=28), 6$ and 7 Years Old

\begin{tabular}{ccccc}
\hline & & Mean & $\begin{array}{c}\text { Standard } \\
\text { deviation }\end{array}$ & $t$ Test $^{a}$ \\
\hline Age (months) & $\mathrm{B}^{b}$ & 90.1 & 4.59 & 1.70 \\
Height & G & 88.2 & 3.73 & \\
(cm) & B & 124.4 & 6.25 & 1.39 \\
Weight & G & 122.4 & 5.70 & \\
(kg) & B & 24.9 & 4.43 & 0.14 \\
Sum of & G & 24.8 & 4.05 & \\
skinfold & B & 30.5 & 15.60 & \\
(mm) & G & 43.3 & 19.36 & \\
Body surface & & & & \\
area $\left(\mathrm{m}^{2}\right)$ & B & 0.93 & 0.074 & \\
\hline
\end{tabular}

${ }^{a} t(64)>1.99$ for $P<0.05$.

${ }^{b} \mathrm{~B}$, boy; G, girl.

(32). The higher percentile score for the girls' weight probably reflects the significantly larger skinfold measure.

No significant $(P>0.05)$ lipid or lipoprotein differences can be observed except for HDL-C which is significantly $(P<0.05)$ higher for the boys when compared with the girls (Table 2). In order to correct for the skinfold differences which may have influenced the HDL-C results, a covariance analysis adjusting for these differences still resulted in significant $(P<0.05)$ adjusted mean scores between the boys and girls (Table 3 ). However, the HDL-C to LDL-C and HDL-C to total cholesterol ratios analyses revealed no sex differences $(P>0.05)$.

As shown in Table 4, the girls' resting heart was higher $(P<0.05)$ than the boys'; but, the preexercise and peak heart rates were not different. The steady-rate exercise heart rate was $9 \%(P<0.05)$ lower for the boys $\left(119 \mathrm{vs} 131\right.$ beats $\left.\cdot \min ^{-1}\right)$. As shown in Table 3, adjusting for skinfold differences still resulted in significant resting and steady-rate heart rate differences between the sexes. The boys also did significantly $(P<0.05)$ more cumulative work $(2093.8 \mathrm{vs} 1596.4 \mathrm{kgm})$ which is the amount of work done for the entire test.

Multiple stepwise forward regression analyses were performed across and between sex with the inclusion of anthropometric, blood pressure, and performance variables to predict each of the lipids and lipoproteins. None of the analyses was significant $(P>0.05)$ except when predicting cholesterol across sex. The prediction equation for cholesterol resulted in the inclusion of only one independent variable $\left(\mathrm{CHOL}=-51.45(\right.$ ln steady-rate $\mathrm{HR})+396.45 ; r^{2}=0.07, \mathrm{SE}= \pm$ $20.01, P<0.05$ ) which accounted for $7 \%$ of the common variance associated with cholesterol.

The multiple regression analysis to predict cumulative work $(\mathrm{kgm})$ from certain resting variables (height, weight, SSF, BSA, heart rate, and systolic and diastolic 
TABLE 2

Comparison of Blood Lipids between Boys $(N=38)$ and Girls $(N=28)$

\begin{tabular}{ccccc}
\hline Variable & & Mean & $\begin{array}{c}\text { Standard } \\
\text { deviation }\end{array}$ & $t$ Test $^{\prime \prime}$ \\
\hline Chol $^{\iota}$ & B $^{r}$ & 152.8 & 20.53 & 1.93 \\
(mg/dl) & G & 143.2 & 19.41 & \\
TG & B & 63.6 & 20.55 & 0.06 \\
(mg/dl) & G & 63.9 & 16.13 & \\
HDL-C & B & 49.6 & 8.04 & 3.35 \\
(mg/d) & G & 43.3 & 6.88 & \\
LDL-C & B & 94.9 & 21.22 & 0.55 \\
(mg/dl) & G & 92.2 & 18.69 & \\
VLDL-TG & B & 29.8 & 15.47 & \\
(mg/dl) & G & 31.9 & 14.76 & 1.46 \\
HDL-C/Chol & B & 0.33 & 0.061 & \\
& G & 0.31 & 0.061 & 1.23 \\
HDL-Cl & B & 0.55 & 0.167 & \\
LDL-C & G & 0.50 & 0.180 & \\
\hline
\end{tabular}

${ }^{a} t(64)>1.99$ for $P<0.05$.

${ }^{b}$ Abbreviations: Chol, cholesterol; TG, triglyceride; HDL-C, high-density lipoprotein cholesterol; LDL-C, low-density lipoprotein cholesterol; VLDL-TG, very low density lipoprotein triglyceride.

B, boy; G, girl.

blood pressure) resulted in a significant $(P<0.05)$ analysis which included BSA, SSF, and weight as the independent measures. As shown in Table 5, these three variables accounted for $33 \%$ of the common variance associated with cumulative work.

After holding the skinfold measurement constant, significant $(P<0.05)$ partial correlations were obtained between LDL-C vs cholesterol and VLDL-TG vs triglycerides for both the boys and girls (Table 6). In addition, a significant inverse

TABLE 3

Comparison for HDl-C, Resting Heart Rate, and Steady-Rate Heart Rate adusting For SKinfold Differences Via an ANalysis of Covariance

\begin{tabular}{|c|c|c|c|c|}
\hline & & ADJ $\bar{\chi}$ & SE & $F$ ratio \\
\hline $\begin{array}{l}\text { HDL-C } \\
\text { (mg/dl) }\end{array}$ & $\begin{array}{l}\text { B } \\
\mathbf{G}\end{array}$ & $\begin{array}{l}49.4 \\
43.4\end{array}$ & $\begin{array}{l}1.27 \\
1.50\end{array}$ & 8.74 \\
\hline $\begin{array}{l}\text { Rest HR } \\
\quad \text { (beats } \cdot \min ^{-1} \text { ) }\end{array}$ & $\begin{array}{l}\text { B } \\
\text { G }\end{array}$ & $\begin{array}{l}83.8 \\
91.1\end{array}$ & $\begin{array}{l}1.83 \\
2.15\end{array}$ & 6.44 \\
\hline $\begin{array}{l}\ln \mathrm{SR}_{\mathbf{H R}}^{b} \\
\quad\left(\text { beats } \cdot \min ^{-1} \text { ) }\right.\end{array}$ & $\begin{array}{l}\text { B } \\
\text { G }\end{array}$ & $\begin{array}{l}4.78 \\
4.87\end{array}$ & $\begin{array}{l}0.016 \\
0.019\end{array}$ & 14.25 \\
\hline
\end{tabular}

${ }^{a} F(1,62) \geqslant 3.99, P \leqslant 0.05$.

${ }^{b}$ Covariance analysis was performed on the natural log transformed values in order to equalize the variances. 
TABLE 4

Comparison of Resting Heart Rate (HR), Blood Pressure (BP), and

Performance Measures for the Boys $(N=38)$ and Girls $(N=28)$

\begin{tabular}{|c|c|c|c|c|}
\hline Variable & & Mean & $\begin{array}{l}\text { Standard } \\
\text { deviation }\end{array}$ & $t$ Test $^{a}$ \\
\hline $\begin{array}{l}\text { Rest HR } \\
\quad \text { (beats } \cdot \min ^{-1} \text { ) }\end{array}$ & $\begin{array}{l}\mathbf{B}^{b} \\
\mathbf{G}\end{array}$ & $\begin{array}{l}84.5 \\
90.1\end{array}$ & $\begin{array}{l}10.67 \\
11.68\end{array}$ & 2.03 \\
\hline $\begin{array}{l}\text { Rest SBPc } \\
(\mathrm{mm} \mathrm{Hg})\end{array}$ & $\begin{array}{l}\text { B } \\
\text { G }\end{array}$ & $\begin{array}{l}92.8 \\
89.9\end{array}$ & $\begin{array}{r}8.17 \\
10.84\end{array}$ & 1.18 \\
\hline $\begin{array}{l}\text { Rest DBP } \\
\qquad(\mathrm{mm} \mathrm{Hg})\end{array}$ & $\begin{array}{l}\text { B } \\
\text { G }\end{array}$ & $\begin{array}{l}61.1 \\
60.2\end{array}$ & $\begin{array}{l}7.72 \\
6.77\end{array}$ & 0.49 \\
\hline $\begin{array}{r}\text { Preexercise HR } \\
\text { (beats } \cdot \min ^{-1} \text { ) }\end{array}$ & $\begin{array}{l}\text { B } \\
\text { G }\end{array}$ & $\begin{array}{l}95.1 \\
96.5\end{array}$ & $\begin{array}{l}12.50 \\
16.34\end{array}$ & 0.37 \\
\hline $\begin{array}{l}\text { SR HR } \\
\left(\text { beats } \cdot \min ^{-1} \text { ) }\right.\end{array}$ & $\begin{array}{l}\text { B } \\
\text { G }\end{array}$ & $\begin{array}{l}119.2 \\
131.2\end{array}$ & $\begin{array}{l}10.52 \\
14.16\end{array}$ & $3.87^{d}$ \\
\hline $\begin{array}{l}\text { SR work } \\
\quad\left(\mathrm{kgm} \cdot \mathrm{min}^{-1}\right)\end{array}$ & $\begin{array}{l}\text { B } \\
\text { G }\end{array}$ & $\begin{array}{l}92.3 \\
91.9\end{array}$ & $\begin{array}{l}4.64 \\
4.12\end{array}$ & 0.24 \\
\hline $\begin{array}{c}\text { Cum work } \\
\text { (kgm) }\end{array}$ & $\begin{array}{l}\text { B } \\
\text { G }\end{array}$ & $\begin{array}{l}2093.8 \\
1596.4\end{array}$ & $\begin{array}{l}516.53 \\
374.33\end{array}$ & $4.58^{d}$ \\
\hline $\begin{array}{l}\text { Peak HR } \\
\quad \text { (beats } \cdot \min ^{-1} \text { ) }\end{array}$ & $\begin{array}{l}\text { B } \\
\text { G }\end{array}$ & $\begin{array}{l}190.1 \\
192.1\end{array}$ & $\begin{array}{l}7.43 \\
9.16\end{array}$ & 0.94 \\
\hline
\end{tabular}

${ }^{a} t(64)>1.99$ for $P<0.05$.

${ }^{b} \mathrm{~B}$, boy; G, girl.

' Abbreviations: SBP, Systolic blood pressure; DPB, diastolic blood pressure; SR, steady rate; Cum, cumulative.

${ }^{d} t$ values were based on the natural log transformed values to equalize the variances.

relationship was obtained between HDL-C vs triglycerides and VLDL-TG for the girls $(r=-0.46$ and $r=-0.40$, respectively).

Physical activity patterns were determined from minute-by-minute heart rate data grouped into 20-beat heart rate categories (Fig. 1). As shown in Fig. 1, the boys show a greater frequency $(56.2$ vs $29.6 \mathrm{~min}$ ) of higher rates (HR $\geqslant 141$ beats $\mathrm{min}^{-1}$ ). There was also a 24.4 -min difference in favor of the boys for the heart rate category of $121-140$ beats $\cdot \mathrm{min}^{-1}$ ). These data indicate that the boys were more actively involved in vigorous physical activity than the girls.

\section{DISCUSSION}

The present investigation screened 66 prepubescent 6 - and 7-year-old boys and girls to compare sex differences for certain CHD risk factors. Comparing the present results with data from previously published population studies indicates that the present sample of children, while small in number, was similar to other representative samples of 6- and 7-year-old, white boys and girls in the United States $(8,30)$.

The mean cholesterol values by sex are slightly lower when compared with other population studies $(12,13,25,29)$. For example, Frerichs reported choles- 
TABLE 5

Multiple Stepwise Regression Analysis Predicting Cumulative Work (kgm) from Selected ANTHRopometric, Cardiovascular, and Bicycle Ergometer Performance Measures ${ }^{\prime \prime}$

\begin{tabular}{lccc}
\hline & \multicolumn{3}{c}{ Independent variable $^{b}$} \\
\cline { 2 - 4 } & BSA & SSF & WT \\
\hline Partial $r$ & -0.11 & -0.40 & 0.30 \\
Regression coefficient & -1977.40 & -17.20 & 148.02 \\
Common variance (\%) & 20 & 6 & 7 \\
Constant & & 653.95 & \\
$\left(r^{2}\right)$ & & 0.33 & \\
SE & & 438.8 & \\
$F$ & & 10.11 & \\
\hline
\end{tabular}

a The order in which the independent variables appear from left to right represents their order of selection.

${ }^{b}$ BSA, Body surface area; SSF, sum of skinfold; WT, body weight.

terol values for 7-year-old boys $(N=96)$ and girls $(N=91)$ of 160.6 and 163.3 $\mathrm{mg} / \mathrm{dl}$, respectively (13). However, when comparing the present cholesterol data with the results of the American Pima Indians of similar ages $(145 \mathrm{mg} / \mathrm{dl}$ for the boys and $155 \mathrm{mg} / \mathrm{dl}$ for the girls), the results were very similar (34). The triglyceride values for this study were in good agreement with those reported in earlier investigations $(29,34)$. For example, the triglyceride values of 62.8 and 64.2 for boys and girls, respectively, were similar to those reported by Morrison (56.0 $\mathrm{mg} / \mathrm{dl}$ for boys and $62.0 \mathrm{mg} / \mathrm{dl}$ for girls) (29).

Morrison reported HDL-C and LDL-C values of 56 and $94 \mathrm{mg} / \mathrm{dl}$ for boys $(N=$ 50) and 40 and $101 \mathrm{mg} / \mathrm{dl}$ for girls $(N=39)$, respectively, ages 6 and 7 years old (30). Apparently, prepubescent boys have higher HDL-C than their female counterparts which accounts for the boys higher total cholesterol values $(12,30)$.

TABLE 6

Partial Correlation Coefficients for Boys (B) and Girls (G) Between the Lipid and Lipoprotein Measures AdJusting for Skinfold Differences

\begin{tabular}{lcccccc}
\hline & & CHOL & HDL-C & LDL-C & TG & VLDL-TG \\
\hline CHOL & & 1.00 & & & & \\
HDL-C & B & 0.26 & 1.00 & & & \\
& G & 0.32 & & & & \\
LDL-C & B & $0.90^{*}$ & -0.12 & 1.00 & & \\
& G & $0.94^{*}$ & 6.07 & & & \\
TG & B & 0.21 & -0.14 & 0.11 & 1.00 & \\
& G & -0.15 & $-0.46^{*}$ & -0.14 & & \\
VLDL-TG & B & 0.14 & -0.02 & -0.00 & $0.85^{*}$ & 1.00 \\
& G & -0.19 & $-0.40^{*}$ & -0.22 & $0.90^{*}$ & \\
\hline
\end{tabular}

* Significant at the 0.05 level: boys, $r \geqslant 0.32, P \leqslant 0.05 ;$ girls, $r \geqslant 0.38, P \leqslant 0.05$. 


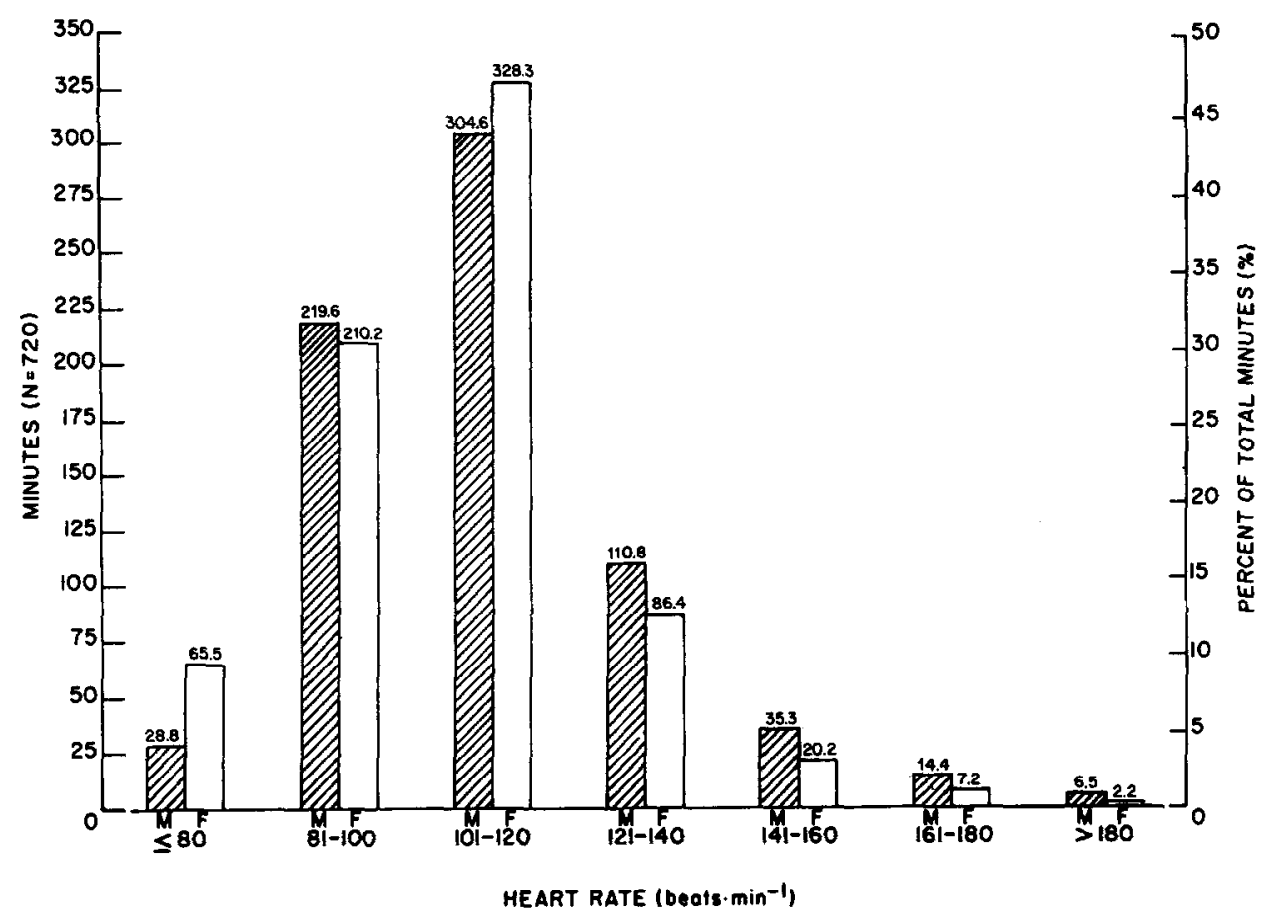

FIG. 1. Twelve-hour ( 8 AM-8 PM) minute-by-minute heart rates recorded during the summer and grouped into 20 beats $\cdot \min ^{-1}$ categories (M, male; F, female).

Similar observations are evident in the present results. One possible explanation for these differences may be due to significant differences in physical activity patterns between the sexes (Fig. 1) (see below). The VLDL-TG values presented are slightly lower than those reported by Ellefson (12). However, the VLDL-TG to total triglyceride ratio of 47 and $50 \%$ for boys and girls, respectively, was similar to the ratios of $51 \%$ for the boys and $50 \%$ for girls reported by Ellefson (12).

The resting systolic and diastolic blood pressure are slightly lower than mean values reported by the National Heart, Lung and Blood Institutes Task Force on Blood Pressure Control in Children (2). Data from the Bogalusa Heart Study show the mean resting systolic/diastolic blood pressures for 7-year-old boys and girls are $95 / 58$ and $93 / 57 \mathrm{~mm} \mathrm{Hg}$, respectively, which are similar to the present data (36).

The difference between the boys and girls for resting and steady-rate heart rates may reflect a higher degree of cardiovascular fitness for the boys. That is, the boys were able to perform a given amount of work at a lower steady-rate heart rate than the girls. Since physical training normally results in lower resting heart rates and lower heart rates for a given absolute submaximum exercise task $(3,27)$, differences in physical activity patterns might account for the lower steady-rate heart rates observed for the boys. Activity patterns are, in fact, different, with the boys having a greater frequency of heart rates in excess of 140 beats $\cdot \min ^{-1}$. In other words, the boys appear to be involved in more vigorous physical activity 
during the day than the girls (16). Although only speculative at this time, the differences in HDL-C observed between the boys and girls also might be explained by the difference in activity patterns (38).

Sex differences for the association between HDL-C and triglycerides are difficult to explain. Correlations of similar magnitude also have been obtained on a separate sample of children ages 7 to 10 years $(r=-0.28, N=90$ boys, $P<0.05 ; r$ $=-0.48, N=39$ girls, $P<0.05$ ) (unpublished data). Srinivasan reported a significant correlation of $r=-0.42$ between $\alpha$-lipoproteins and triglyceride for a population of 2,009 males and females ages 5 to 14 years (35). Correlations ranging from $r=-0.33$ to $r=-0.77$ have been reported for both men and women in several adult studies $(1,4,17,21,28)$. A strong inverse relationship between HDL-C and triglycerides in adults is suggestive of "protection" against Type IV hyperlipoproteinemia (18). However, the frequency of Type IV hyperlipoproteinemia in the present study for the boys was similar to that of the girls (1 vs 2, respectively). Furthermore, reciprocal changes of HDL-C and VLDL-TG have been induced by different modalities such as exercise and high-carbohydrate diet (33). Although the boys demonstrated a higher level of physical activity than the girls, only a weak inverse relationship was obtained.

The multiple regression analyses show the predictability of plasma lipids and lipoproteins from certain anthropometric, blood pressure, and bicycle ergometric measures is very low. Furthermore, predicting total work $(\mathrm{kgm})$ from certain resting cardiovascular and anthropometric variables also resulted in a significant but weak prediction equation.

In summary, it appears the anthropometric, blood lipid and lipoprotein, and resting blood pressure data agree with data from existing literature. Sex differences were apparent for HDL-C, resting and steady-rate heart rate and were attributed to physical activity patterns since the boys were significantly more active than the girls. Furthermore, these sex differences still existed when correcting for higher skinfold measures in the girls. It is apparent that significant single-order correlations exist in prepubescent children among HDL-C and triglycerides and that these correlations may differ by sex. Multiple regression analyses also were performed with each lipid and lipoprotein measure used as a dependent variable, but no meaningful results were obtained.

Implications for the present findings are as follows:

a. Involvement in vigorous physical activity programs at an early age may be beneficial in reducing CHD risk in children.

b. Since body size (BSA, SSF, and WT) accounted for 33\% of the variance associated with cumulative work, the effects of physical activity on reducing body fatness may also improve work performance.

c. To study the effects of a longitudinal vigorous physical activity program on HDL-C in boys and girls, particularly during pubescence, to determine what effect physical activity may have on HDL-C for the boys since puberty results in a lowering of HDL-C for boys.

\section{ACKNOWLEDGMENT}

The authors wish to acknowledge Mr. Kenneth Guire from the Statistical Research Laboratory at the University of Michigan for his assistance in the statistical analyses. 


\section{REFERENCES}

1. Albers, J. J., Cheung, C. C., and Hazzard, W. H. High density lipoproteins in myocardial infarction survivors. Metabolism 10, 479-485 (1978).

2. American Academy of Pediatrics. Report of the Task Force on Blood Pressure Control in Children. Pediatrics (Suppl.) 59, Part 2 (1977).

3. Astrand, P. O., and Rodahl, K. "Textbook of Work Physiology," pp. 455-459. McGraw-Hill, New York, 1977.

4. Barboriak, J. J., Anderson, A. J., and Hoffman, R. G. Interrelationship between coronary artery occlusion, high density lipoprotein cholesterol and alcohol intakc. J. Lab. Clin. Med. 94, 348-353 (1979).

5. Behnke, A. R., and Wilmore, J. H. "Evaluation and Regulation of Body Build and Composition." Prentice-Hall, Englewood Cliffs, N.J., 1974.

6. Block, W. D., Jarrett, K. J., and Levine, J. B. An improved automated determination of serum total cholesterol with a single color reagent. Clin. Chem. 12, 681-687 (1966).

7. Block, W. D., and Jarrett, K. J. An automated technique for the quantitative determination of serum total triglycerides. Amer. J. Med. Technol. 35, 1 (1969).

8. Christensen, B., Glueck, C., Kwiterovich, P., et al. Plasma cholesterol and triglyceride distributions in 13,665 children and adolescents: The prevalence study of the Lipid Research Clinics program. Pediatr. Res. 14, 194-202 (1980).

9. Court, J. M., Dunlop, M., and Leonard, R. F., Plasma lipid values in childhood obesity. Aust. Paediatr. J. 10, 10-14 (1974).

10. Court, J. M., Hill, G. J., Dunlop, M., et al. Hypertension in childhood obesity. Aust. Paediatr. J. 10, 296-300 (1974).

11. DuBois, D., and DuBois, E. F. A formula to estimate the approximate surface area if height and weight be known. Arch. Intern. Med. 17, 803-811 (1916).

12. Ellefson, R., Elveback, L. R., Hodgson, P. A., et al. Cholesterol and triglycerides in serum lipoproteins of young persons in Rochester, Minnesota. Mayo Clin. Proc. 58, 307-320 (1978).

13. Frerichs, R. R., Srinivasan, S. R. Webber, L. S., et al. Serum cholesterol and triglyceride levels in 3,446 children from a biracial community. Circulation 54, 302-308 (1976).

14. Gilliam, T. B., Katch, V. L., Thorland, W. G., et al. Prevalence of coronary heart disease risk factors in active children, 7 to 12 years of age. Med. Sci. Sports 9, 21-25 (1977).

15. Gilliam, T. B., Thorland, W. G., Sady, S., et al. Blood lipids and fatness in children age 7-13. Canad. J. Appl. Sport Sci. 3, 65-69 (1978).

16. Gilliam, T. B., Freedson, P. S., Geenen, D. L., and Shahraray, B. Physical activity patterns as determined by heart rate monitoring in six to seven year old children. Med. Sci. Sports Exercise, 13, 65-67 (1981).

17. Gordon, T., Castelli, W. P., Hjortland, M. C., et al. High density lipoprotein as a protective factor against coronary heart disease, The Framingham study. Amer. J. Med. 62, 707-714 (1977).

18. Gotto, A. M., DeBakey, M. E., Foreyt, J. P., et al. Dietary treatment of Type IV hyperlipoproteinemia. JAMA 237, 1212-1215 (1977).

19. Hamilton, P., and Andrew, G. M. Influence of growth and athletic training on heart and lung function. Eur. J. Appl. Physiol. 36, 27-38 (1978).

20. Hatch, F. T., and Lees, R. S. Practical methods for plasma lipoprotein analysis. Advan. Lipid Res. 6, 1-67 (1968).

21. Hulley, S. B., Cohen, R., and Widdowson, G. Plasma high-density lipoprotein cholesterol level: Influence of risk factor intervention. JAMA 238, 2269-2271 (1977).

22. Kannel, W. B. Coronary risk factors. I: Recent highlights from the Framingham study. Symposium on Cardiovascular Epidemiology, Aust. N.Z. J. Med. 6, 373-386 (1976).

23. Kobayashi, K., Kitamura, K., Miura, M., et al. Aerobic power as related to body growth and training in Japanese boys A longitudinal study. J. Appl. Physiol. 44, 666-672 (1978).

24. Kwiterovich, P. A., Chase, G. A., and Bachorik, P. S. The Columbia population study. I. Plasma cholesterol and triglyceride levels. Johns Hopkins Med. J. 143, 32-42 (1978).

25. Lauer, R. M., Connor, W. E., Leaverton, P. E., et al. Coronary heart disease risk factors in school children. The Muscatine study. J. Pediatr. 86, 697-706 (1975). 
26. "Manual of Laboratory Operations, LRC Program," Vol. I, "Lipid and Lipoprotein Analysis." DHEW Publication No. (NIH) 75, 628 (1974).

27. Mayers, N., and Gutin, B. Physiological characteristics of elite pre-pubertal cross-country runners. Med. Sci. Sports 11, 172-176 (1979).

28. Miller, C. J., and Miller, N. E. Plasma high density lipoprotein concentration and development in ischaemic heart disease. Lancet, January, 16-19, 1975.

29. Morrison, J. A., deGroot, I., Edwards, B. K., et al. Plasma cholesterol and triglyceride levels in 6775 school children, age 6 to 17. Metabolism 26, 1100-1211 (1977).

30. Morrison, J. A., deGroot, I., Edwards, B. K., et al. Lipids and lipoproteins in 927 school children, ages 6 to 17 years. Pediatrics 62, 990-995 (1978).

31. Morrison, J. A., Laskarzewski, P. M., Rauh, J. L., et al. Lipids lipoproteins, and sexual maturation during adolescence: The Princeton maturation study. Metabolism 28, 641-649 (1979).

32. National Center for Health Statistics: NCHA Growth Charts, 1976. Monthly Vital Statistics Report. Vol. 25 No. 3, Suppl. (HRA 76-1120), Rockeville, Md., 1976.

33. Nikkila, E. A. Metabolic and endocrine control of plasma high density lipoprotein concentration, in "High Density Lipoproteins and Atherosclerosis" (A. M. Gooty, N. E. Miller, and M. F. Oliver, Eds.), pp. 177-192. Elsevier/North-Holland, New York, 1978.

34. Savage, P. J., Hamman, R. F., Bartha, G., et al. Serum cholesterol levels in American (Pima) Indian children and adolescents. Pediatrics 58, 274-282 (1976).

35. Srinivasan, S. R., Frerichs, R. R., Webber, L. S., et al. Serum lipoprotein profile in childhood from a biracial community. Circulation 54, 309-318 (1976).

36. Voors, A. W., Foster, T. A., Frerichs, R. R., et al. Studies of blood pressures in children ages 5-14 years, in a total biracial community. Circulation 54, 319-327 (1976).

37. Wilmore, J. H., and McNamara, J. J. Prevalence of coronary disease risk factors in boys, 8 to 12 years of age. J. Pediatr. 84, 527-533 (1974)

38. Wood, P., and Haskel, W. L. The effect of exercise on plasma high density lipoproteins. Lipids 14, 417-427 (1979). 